\title{
Autoantibody profile in individuals with chronic hepatitis $C$
}

\author{
Maíra Luciana Marconcini ${ }^{[1]}$, Leonardo Fayad ${ }^{[1]}$, Maria Beatriz Cacese Shiozawa ${ }^{[2]}$, \\ Esther Buzaglo Dantas-Correa ${ }^{[1]}$, Leonardo de Lucca Schiavon ${ }^{[1]}$ \\ and Janaína Luz Narciso-Schiavon ${ }^{[1]}$
}

[1]. Núcleo de Estudos em Gastroenterologia e Hepatologia, Universidade Federal de Santa Catarina, Florianópolis, SC. [2]. Departamento de Patologia, Universidade Federal de Santa Catarina, Florianópolis, SC.

\begin{abstract}
Introduction: Autoantibodies are often produced during infection with chronic hepatitis $\mathrm{C}$ virus (HCV), but it remains controversial whether they influence the biochemical profile and histological features of this disease. Therefore, this current study sought to describe these autoantibodies and evaluate their impact on the clinical and histological presentation of hepatitis C. Methods: This cross-sectional analytical study assessed patients with HCV (RNA+) from October 2011 to July 2012. Results: This study included 66 patients, with a mean age of $53.2 \pm 10.5$ years. Of these patients, $60.6 \%$ were male, and $54.3 \%$ presented with genotype 1 . Non-organ-specific autoantibodies (NOSA) were detected in $24 \%$ of the patients; of these, $7.6 \%$ were anti-mitochondrial antibodies (AMA+), $26.7 \%$ were anti-smooth muscle antibodies (SMA + ) and 6.8\% were liver kidney microsomal type 1 antibodies (LKM1+). With respect to the thyroid autoantibodies, 7.4\% were anti-peroxidase (ATPO+) antibodies, and none were anti-thyroglobulin (ATG+) antibodies. Regarding celiac disease autoantibodies, 5.8\% were endomysial antibodies (EMA+), and no transglutaminase (TTG+) antibodies were detected. Cryoglobulins were found in $2.1 \%$ of patients. When NOSA+ individuals were compared to patients without the presence of NOSAs, they exhibited higher median alkaline phosphatase ( 0.7 vs. $0.6 \mathrm{xULN} ; \mathrm{p}=0.041)$, lower median platelet counts $\left(141,500.0 \mathrm{vs} .180,500.0 / \mathrm{mm}^{3}\right.$; $\mathrm{p}=0.036)$, lower mean prothrombin activity $(72.6 \pm 11.5 \%$ vs. $82.2 \pm 16.0 \%$; $\mathrm{p}=0.012)$ and an increased prevalence of significant fibrosis $(\mathrm{E} \geq 2)(45.5 \%$ vs. $18.2 \%$; $=0.012)$. There was also a tendency for a greater proportion of NOSA+ cases to have marked periportal activity $(\mathrm{APP} \geq 3)(44.5 \%$ vs. $15.6 \%$; $=0.087)$. Conclusions: In addition to the high prevalence of autoantibodies associated with HCV infection, it was observed that NOSA positivity was associated with a more severe histological and biochemical profile of hepatitis $\mathrm{C}$ infection.
\end{abstract}

Keywords: Hepatitis C. Autoimmunity. Cryoglobulins. Celiac disease.

\section{INTRODUCTION}

Hepatitis $\mathrm{C}$ virus (HCV) has significant relevance worldwide to the development of chronic liver disease, and it has a high impact on the social, economic and personal lives of those affected. According to the World Health Organization (WHO), approximately $3 \%$ of the global population, approximately 170 million people, are infected with HCV. Brazil has intermediary endemicity, with a prevalence of infection between 2.5 and $10 \%{ }^{1}$. Furthermore, this disease is a serious public health problem because of the high rates of chronicity ${ }^{2}$ and the high potential for evolution to cirrhosis ${ }^{3}$ and hepatocarcinoma ${ }^{4}$.

In addition to the liver damage caused by HCV, findings in recent years have demonstrated that $\mathrm{HCV}$ may be involved in the loss of tolerance to self-antigens and may thereby promote selfreactivity. The relationship between infection and autoimmune

Address to: Dra. Janaína Luz Narciso-Schiavon. Depto. de Clínica Médica/ HU Polydoro Ernani de São Thiago/UFSC. Rua Prof. Maria Flora Pausewang $\mathrm{s} / \mathrm{n} / 3^{\circ}$ andar, Trindade, 88040-900 Florianópolis, SC, Brasil.

Phone: 5548 3721-9014

e-mail: janaina.narciso@uol.com.br

Received 19 February 2012

Accepted 08 April 2013 diseases has been described in cases of mixed cryoglobulinemia, lichen planus, Sjögren's Syndrome, membranoproliferative glomerulonephritis and autoimmune thyroiditis ${ }^{5}$. In addition to the prevalence of these diseases, an imbalance of the immune system may be highlighted by the high prevalence of non-organ specific autoantibodies (NOSA) detected in individuals infected with $\mathrm{HCV}^{6}$. Each of these antibodies is directed against an intracellular antigen that is presented to the immune system when cell death occurs ${ }^{7}$, and this could explain the mechanism by which the virus may be associated with numerous antibodies that react with a variety of cellular components.

The first autoantibody to be associated with hepatitis $\mathrm{C}$ was the liver kidney microsomal type 1 (anti-LKM1) ${ }^{8}$ antibody, which is directed against different epitopes on cytochrome $\mathrm{P} 450^{9}$ and is rarely found in $\mathrm{HCV}$ infection ${ }^{10}$. In addition, anti-smooth muscle antibodies (SMAs) constitute a heterogeneous group of antibodies that react with antigens of the cytoskeleton of smooth muscle cells $s^{6}$, and anti-nuclear antibodies (ANAs) can be found in up to $25 \%$ of $\mathrm{HCV}$ carriers and are frequently related to epiphenomena related to increased histological inflammatory activity $^{11,12}$. The clinical significance of NOSA in patients with hepatitis $\mathrm{C}$ remains poorly defined.

$\mathrm{HCV}$ has been related to the development of disorders of clonal proliferation of B lymphocytes, with mixed cryoglobulinemia being the most common. This disorder occurs in approximately $50 \%$ of patients with chronic $\mathrm{HCV}$ infection $^{13,14}$. 
With respect to the presence of organ-specific antibodies, it has been postulated that $\mathrm{HCV}$ can induce immunologic intolerance to gluten in susceptible individuals, but it is controversial whether the prevalence of celiac disease and endomysial antibodies (EMA) and tissue transglutaminase (TTG) antibodies is higher in patients with hepatitis $\mathrm{C}^{15-17}$. In addition to the increased incidence of autoimmune disease of the thyroid in patients with $\mathrm{HCV}$, a greater prevalence of antiperoxidase (ATPO) and anti-thyroglobulin (ATG) autoantibodies has been noted in these individuals ${ }^{18,19}$.

Given the frequent occurrence of autoantibodies in patients with chronic hepatitis $\mathrm{C}$, this study sought to assess the prevalence of autoantibodies and cryoglobulins in patients with $\mathrm{HCV}$ as well as the correlation between the presence of autoantibodies and the clinical, laboratorial and histological aspects of disease.

\section{METHODS}

This descriptive, cross-sectional study included consecutive anti-HCV positive adult patients seen at the Gastroenterology and Hepatology Outpatient Clinic in our institution between October 2011 and July 2012. These patients provided written, informed consent to participate in the study. HCV infection was defined as a positive HCV-ribonucleic acid (HCV-RNA) result by polymerase chain reaction (PCR) $(25 \mathrm{IU} / \mathrm{mL})$. Negative HCV-RNA individuals and those with incomplete clinical and laboratory data in their medical records were excluded from the study.

The individuals included in the study were analyzed for their clinical and epidemiological characteristics. The clinical, laboratory and histological findings were collected from the medical records data and transferred to a specific protocol. The following variables were studied: age; gender; viral genotype; viral load; diabetes mellitus; systemic arterial hypertension; dyslipidemia; hypothyroidism; hepatitis B surface antigen (HBsAg); antibody to hepatitis B core antigen (anti-HBc); antibody to human immunodeficiency virus (antiHIV); treatment-naïve status; the levels of serum creatinine, hemoglobin, platelets, ferritin and transferrin saturation, aspartate aminotransferase (AST), alanine aminotransferase (ALT), alkaline phosphatase (AP), gamma-glutamyltransferase (GGT), direct bilirubin and serum albumin; prothrombin activity; and levels of ANA, SMA, LKM1, cryoglobulins, ATPO, ATG, EMA, TTG and immunoglobulin A (IgA). The presence of cryoglobulins was considered positive or negative in each sample. The tests of hepatic biochemistry, including the levels of AST, ALT, AP and GGT, were expressed in times the upper limit of normal (xULN). According to the national consensus on the classification of chronic hepatitis ${ }^{20}$, the following histological characteristics were examined in liver biopsies: significant fibrosis (defined as structural changes of stage 2,3 or 4) and marked inflammatory activity (defined as periportal activity of stage 3 or 4). The indirect immunofluorescence technique was used to obtain results for ANA, SMA, LKM1 and EMA. The ELISA technique was implemented for the analysis of TTG, and the chemiluminescence test was applied for identification of ATG and ATPO antibodies. The individuals with positive serology for ANA, SMA and/or LKM1 (titration greater or equal to 1:40) were defined as NOSA-positive.

\section{Statistical analysis}

Continuous variables were described by measures of central and dispersion tendency, while categorical variables were described in absolute numbers and proportions. The means of continuous variables were compared using the Student's $t$ test or the MannWhitney statistic-test. When appropriate, the association between the categorical variables was evaluated using the chi-square test or Fisher's exact test. P values less than 0.05 were considered statistically significant. All tests were two-tailed and conducted using the statistical program Statistical Package for the Social Sciences (SPSS) version 17.0 (SPSS; Chicago; Illinois; USA).

\section{Ethical considerations}

This study protocol conformed to the ethical guidelines of the 1975 Helsinki Declaration and was approved by our institutional review board under number 120,181.

\section{RESULTS}

\section{Patients' characteristics}

From October 2011 to July 2012, 108 patients in the Gastroenterology Outpatient Clinic who presented positive serology results for hepatitis $\mathrm{C}$ were assessed for inclusion in this study. Thirty-nine patients were excluded from this study because their ANA was not plated, and 3 were excluded for presenting a sustained virologic response (Figure 1).

This study included 66 hepatitis $C$ patients with a mean age \pm standard deviation (and median) of $53.2 \pm 10.5$ (53.0) years. Of these patients, $60.6 \%$ were male, and $54.3 \%$ presented genotype 1 , whereas $45.7 \%$ presented genotype 3 (Table 1). None of the

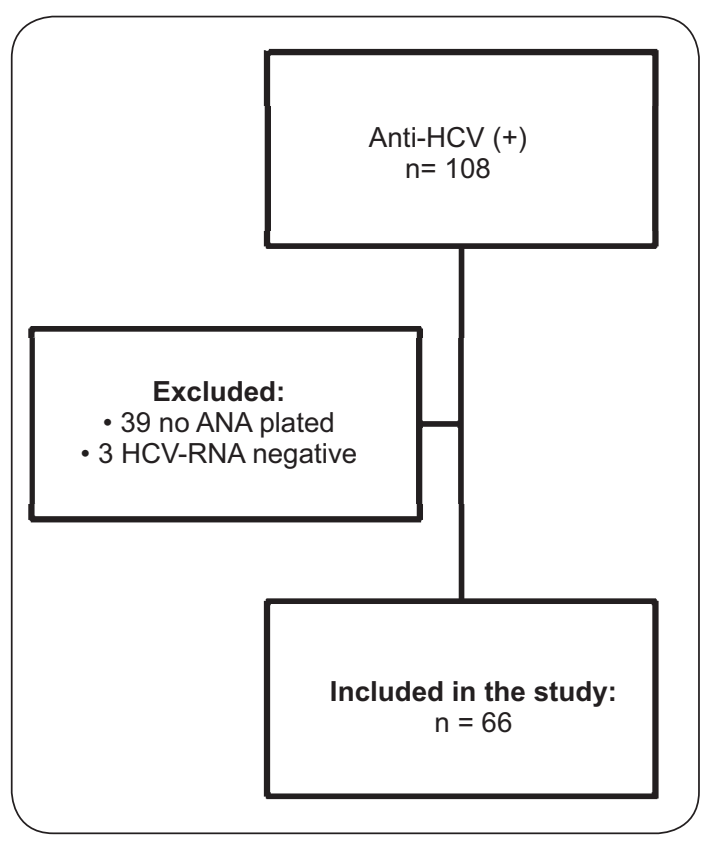

FIGURE 1 - Flow chart of potential candidates for inclusion in the study, exclusion criteria and individuals included. Anti-HCV: antibody to hepatitis $\mathrm{C}$ virus ; $\mathrm{ANA}$ : antinuclear antibody; HCV-RNA: hepatitis C virus-ribonucleic acid. 
TABLE 1 - Distribution of clinical and laboratorial variables in 66 individuals with chronic HCV infection according to NOSA positivity

\begin{tabular}{|c|c|c|c|c|}
\hline & & NOSA $(+)$ & NOSA (-) & \\
\hline Characteristics & Total & $\mathrm{N}=16$ & $\mathrm{~N}=50$ & $\mathrm{p}$ \\
\hline Age (years)* & $53.2 \pm 10.5$ & $56.3 \pm 9.9$ & $52.3 \pm 10.6$ & $0.188^{\mathrm{t}}$ \\
\hline Male (\%) & 60.6 & 56.3 & 62.0 & $0.682 q$ \\
\hline Genotype $1(\%)$ & 54.3 & 53.8 & 54.5 & $0.966 \mathrm{q}$ \\
\hline Viral load $\left(\times 10^{6} \mathrm{UI} / \mathrm{mL}\right)^{\#}$ & 1.10 & 1.05 & 1.13 & $0.696^{\mathrm{m}}$ \\
\hline Diabetes mellitus (\%) & 14.1 & 6.3 & 16.7 & $0.430^{\mathrm{f}}$ \\
\hline Hypertension (\%) & 21.9 & 31.3 & 18.8 & $0.312^{\mathrm{f}}$ \\
\hline Dyslipidemia (\%) & 9.5 & 6.3 & 10.6 & $1.000^{\mathrm{f}}$ \\
\hline Hypothyroidism (\%) & 14.1 & 6.3 & 16.7 & $0.430^{\mathrm{f}}$ \\
\hline HBsAg $(+)(\%)$ & 1.7 & 0.0 & 2.2 & $1.000^{\mathrm{f}}$ \\
\hline Anti-HBc (+) (\%) & 21.7 & 0.0 & 27.8 & $0.089^{f}$ \\
\hline Anti-HIV $(+)(\%)$ & 3.4 & 12.5 & 0.0 & $0.070^{\mathrm{f}}$ \\
\hline Treatment naïve (\%) & 54.0 & 37.5 & 59.6 & $0.126 \mathrm{q}$ \\
\hline Creatinine $(\mathrm{mg} / \mathrm{dL})^{\#}$ & 0.9 & 0.9 & 0.9 & $0.705^{\mathrm{m}}$ \\
\hline Hemoglobin $(\mathrm{g} / \mathrm{dL})^{*}$ & $14.0 \pm 1.9$ & $13.3 \pm 2.1$ & $14.3 \pm 1.8$ & $0.064^{t}$ \\
\hline Platet count $\left(\mathrm{x} 10^{3} / \mathrm{mm}^{3}\right)^{\#}$ & 165.0 & 141.5 & 180.5 & $0.036^{\mathrm{m}}$ \\
\hline Ferritin $(\mathrm{ng} / \mathrm{mL})^{\#}$ & 326.0 & 170.0 & 347.0 & $0.474^{\mathrm{m}}$ \\
\hline Transferrin saturation (\%)* & $41.2 \pm 16.6$ & $35.5 \pm 10.7$ & $43.5 \pm 18.1$ & $0.113^{\mathrm{t}}$ \\
\hline AST (xULN)* & $2.0 \pm 1.6$ & $2.4 \pm 2.3$ & $1.8 \pm 1.2$ & $0.336^{\mathrm{t}}$ \\
\hline ALT (xULN) \# & 1.2 & 1.0 & 1.4 & $0.515^{\mathrm{m}}$ \\
\hline $\mathrm{AP}(\mathrm{xULN})^{\#}$ & 0.6 & 0.7 & 0.6 & $0.041^{\mathrm{m}}$ \\
\hline GGT (xULN) & 0.9 & 0.8 & 1.0 & $0.738^{m}$ \\
\hline Direct bilirubin $(\mathrm{mg} / \mathrm{dL})^{\#}$ & 0.2 & 0.2 & 0.2 & $0.273^{\mathrm{m}}$ \\
\hline Albumin $(g / d L)^{*}$ & $3.7 \pm 0.5$ & $3.6 \pm 0.4$ & $3.7 \pm 0.5$ & $0.304^{t}$ \\
\hline Prothrombin activity $(\%)^{*}$ & $79.9 \pm 15.5$ & $72.6 \pm 11.5$ & $82.2 \pm 16.0$ & $0.012^{\mathrm{t}}$ \\
\hline
\end{tabular}

$\mathrm{HCV}$ : hepatitis C virus; NOSA: non-organ specific autoantibodies; HBsAg: hepatitis B surface antigen; anti-HBc: antibodies to hepatitis B core antigen; anti-HIV: antibodies to human immunodeficiency virus; AST: aspartate aminotransferase; ALT: alanine aminotransferase; AP: alkaline phosphatase; GGT: gama-glutamyltransferase; xULN: times the upper limit of normal; ${ }^{*}$ mean \pm standard deviation; ${ }^{\mathrm{m}}$ median; ${ }^{\mathrm{t}}$ Student's $t$ test; $\mathrm{m}_{\text {Mann-Whitney; }} \mathrm{q}_{\text {chi-square test; }}{ }^{\mathrm{f}}$ Fisher's exact test.

patients presented genotype 2. One patient was HBsAg positive, and 2 individuals were reactive for anti-HIV antibodies. Among the 44 subjects who underwent liver biopsy, cirrhosis (structural change grade 4) was found in $13.6 \%$. With respect to the laboratory characteristics, the individuals demonstrated mean, standard deviation and median values for ALT of $1.6 \pm 1.2(1.2) \mathrm{x}$ $\mathrm{ULN}$; direct bilirubin of $0.6 \pm 0.2(0.2) \mathrm{mg} / \mathrm{dL}$; albumin of $3.7 \pm 0.5$ $(3.8 \mathrm{~g} / \mathrm{dL}$; international normalised ratio (INR) of $1.1 \pm 0.1(1.0)$ and platelet counts of $171,893.9 \pm 85,039.9(165,500.00) / \mathrm{mm}^{3}$.

\section{Analysis of autoantibodies}

Regarding autoantibody positivity (Figure $\mathbf{2}$ and Table 2), $5 / 66(7.6 \%)$ patients were ANA reactive; of these, 3 reacted with fine speckled patterns, 1 had a homogeneous pattern,

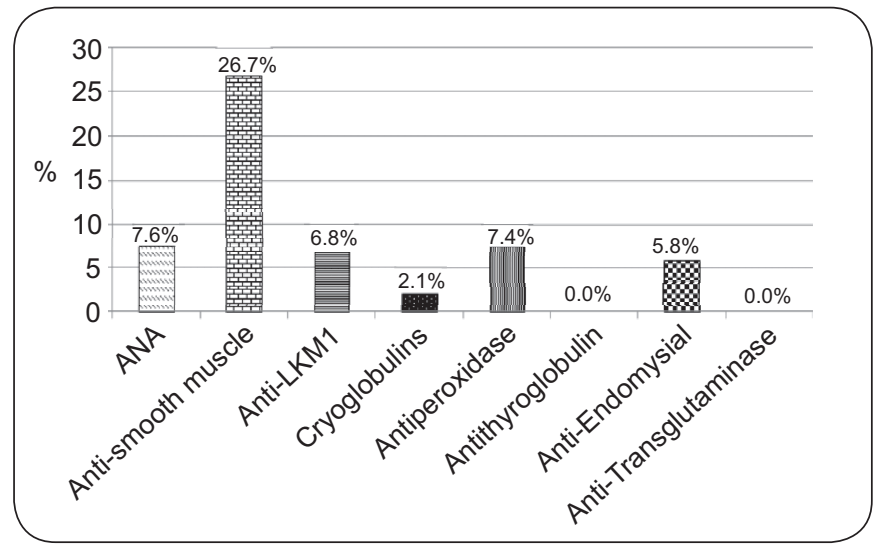

FIGURE 2 - Distribution of autoantibodies in 66 individuals with hepatitis C. ANA: antinuclear antibody; LKM1: liver kidney microsomal type 1 antibody.

TABLE 2 - Distribution of NOSA positivity in 66 individuals with chronic $\mathrm{HCV}$ infection

\begin{tabular}{ccccc}
\hline & NOSA & & Number & Percentage \\
\hline ANA (+) & ASM (-) & LKM1 (-) & 3 & 4.5 \\
ANA (+) & ASM (+) & LKM1 (-) & 1 & 1.5 \\
ANA (+) & ASM (+) & LKM1 (+) & 1 & 1.5 \\
ANA (-) & ASM (+) & LKM1 (-) & 9 & 13.6 \\
ANA (-) & ASM (+) & LKM1 (+) & 1 & 1.5 \\
ANA (-) & ASM (-) & LKM1 (+) & 1 & 1.5 \\
\hline
\end{tabular}

HCV: hepatitis C virus; NOSA: non-organ specific autoantibodies; ANA: anti-nuclear antibody; ASM: anti-smooth muscle antibody; LKM1: liver kidney microsomal type 1 antibody.

and 1 had with a nucleolar pattern. The anti-SMA antibody level was positive in $12 / 45(26.7 \%)$ of the individuals, and LKM1 antibodies were detected in $3 / 44(6.8 \%)$ of the cases. Cryoglobulins were positive in $1 / 48(2.1 \%)$ of the patients. Regarding the thyroid autoantibodies, ATPO autoantibodies were detected in $4 / 54(7.4 \%)$ of the patients, whereas ATG antibodies were detected in none of the patients $(0 / 48)$. Concerning the antibodies present in celiac disease, EMA was reactive in 3/52 (5.8\%) individuals, but TTG was not reactive in any of the patients (0/34). No patient presented IgA deficiency.

\section{Comparative analysis according to autoantibody positivity}

When comparing the patients with NOSA positivity to those without NOSA positivity (Table 1), the positive individuals had a higher median level of AP ( 0.7 vs. $0.6 \times U L N ; p=0.041)$, lower median platelet count $\left(141,500.0\right.$ vs. $180,500.0 / \mathrm{mm}^{3}$; $\mathrm{p}=0.036)$ and lower mean prothrombin activity $(72.6 \pm 11.5 \%$ vs. $82.2 \pm 16.0 \%$; $\mathrm{p}=0.012)$. In addition, for the histological characteristics (Table 3) evaluated in the liver biopsy, there was a higher proportion of NOSA-positive individuals with significant fibrosis $(72.7 \%$ vs. $27.3 \%$; $p=0.012)$ and a tendency towards a greater proportion of these individuals with marked periportal inflammatory activity $(44.4 \%$ vs. $15.6 \% ; \mathrm{p}=0.087)$. No differences were found between NOSA-positive and -negative 
individuals in regards to age, gender, genotype, viral load, comorbidities (diabetes mellitus, hypertension, dyslipidemia and hypothyroidism), serology (HBsAg+, anti-HBc+, anti-HIV+), treatment-naïve status and levels of creatinine, hemoglobin, ferritin, transferrin saturation, AST, ALT, GGT, direct bilirubin and albumin.

TABLE 3 - Distribution of histological variables for 44 individuals with hepatitis C according to NOSA positivity

\begin{tabular}{|c|c|c|c|c|c|c|c|}
\hline \multirow[b]{2}{*}{ Characteristics } & \multicolumn{2}{|c|}{ Total } & \multicolumn{2}{|c|}{$\operatorname{NOSA}(+)$} & \multicolumn{2}{|c|}{ NOSA (-) } & \multirow[b]{2}{*}{ p } \\
\hline & $\mathrm{n}$ & $\%$ & $\mathrm{n}$ & $\%$ & $\mathrm{n}$ & $\%$ & \\
\hline Significant fibrosis* & 17 & 38.6 & 8 & 72.7 & 9 & 27.3 & $0.012^{\mathrm{f}}$ \\
\hline Marked periportal activity $\#$ & 9 & 22.0 & 4 & 44.4 & 5 & 15.6 & $0.087^{\mathrm{f}}$ \\
\hline
\end{tabular}

NOSA: non-organ specific autoantibodies; f: Fisher's exact test; *structural changes $\geq 2$; "periportal activity $\geq 3$.

\section{DISCUSSION}

Previous studies, as well as the current study, have shown that in Brazil and worldwide, hepatitis C more commonly affects individuals who are between the fourth and fifth decades of life (38 to $42 \%)^{21,22}$; in addition, the majority of those affected are male $(60.5 \text { to } 76 \%)^{21,23}$, and cirrhosis is present in 4 to $21 \%$ of patients ${ }^{3,24}$. In Brazil, HCV genotype 1 is associated with prevalence rates that vary between 50.3 and $88.5 \%$, while genotype 2, which was not detected in this study, has a lower prevalence rate that ranges between 0.7 and $8.8 \%{ }^{25}$.

Serum autoantibodies are commonly found in patients with hepatitis $\mathrm{C}^{6}$. Regarding thyroid autoantibodies, the current study found a 7\% prevalence of ATPO antibodies, which is similar to that described by previous authors. No patient presented positivity for ATG, which is frequently reported at lower prevalence rates than ATPO. Fernandez-Soto et al. compared the presence of antithyroid antibodies in 134 patients with $\mathrm{HCV}$ and 41 patients with hepatitis B virus (HBV) and described a higher prevalence of ATPO (20\% vs. $5 \%$; $=0.020)$ and ATG positivity $(11 \%$ vs. $3 \%$; $\mathrm{p}=0.040)$ and higher levels of TSH after interferon treatment $(12 \%$ vs. $3 \%$; $p=0.030$ ) among $\mathrm{HCV}$ patients. Furthermore, individuals with a positive ATPO status pre-treatment have been shown to have a higher risk of developing thyroid dysfunction during the post-treatment period $(\mathrm{p}=0.030)^{19}$. Ganne-Carrie et al. evaluated 97 patients with $\mathrm{HCV}$ and compared them to a control group and showed that microsomal and/or ATPO antibodies were detected in $12.4 \%$ vs. $3 \%$ of patients, respectively $(\mathrm{p}<0.02)^{26}$. In a study employing second generation ELISA tests, Duclos-Vallee et al. examined 200 patients with thyroid disease to determine the prevalence of $\mathrm{HCV}$; among 50 individuals with simple goiter, none were anti-HCV-positive; among 50 individuals with serious goiter, 2 were positive; among 5 individuals with myxedema, 2 were positive; and among 50 patients with Hashimoto's thyroiditis, 12 were positive. HCV may be involved in the initial process of autoimmunity, but this hypothesis has not been proven ${ }^{27}$. Recently, Yang et al. compared 462 individuals with ATPO antibodies and/ or ATG positivity to 360 individuals with antibody negativity and reported no difference in the prevalence of anti-HCV positivity between the 2 groups $(1.3 \% \text { vs. } 0.53 \% ; p>0.05)^{28}$.

Because of the higher prevalence of celiac disease in patients with $\mathrm{HCV}^{16}$, it has been hypothesized that $\mathrm{HCV}$ may induce immunologic intolerance to gluten in susceptible individuals. In 2001, Fine et al. compared the prevalence of anti-gliadin antibodies, EMA and TTG in 5 groups and found a higher prevalence of anti-gliadin antibodies among patients with liver disease. Furthermore, only patients with hepatitis $\mathrm{C}(\mathrm{n}=3 ; 1.2 \%)$ and autoimmune liver disease $(\mathrm{n}=2 ; 3.4 \%)$ presented positive EMA or TTG results. Also, one of the healthy volunteers showed positive anti-gliadin antibody, EMA and TTG results, and this individual was later diagnosed with hepatitis $\mathrm{C}^{29}$. Ruggeri et al. assessed 244 patients with HCV infection (HCV-RNA positive) and 121 patients with HBV for the presence of TTG antibodies (the positive patients were additionally tested for EMA) and compared the results to those of 1,230 blood donors screened for celiac disease. EMA antibodies were detected in $2 \%$ of the patients with $\mathrm{HCV}$, in $0.8 \%$ of the patients with $\mathrm{HBV}$ and in $0.16 \%$ of the blood donors, with a significant statistical difference between patients with $\mathrm{HCV}$ and blood donors $(p=0.02)^{15}$. Thevenot et al. tested 624 patients with chronic hepatitis $\mathrm{C}$ for EMA and anti-gliadin antibodies, and the results showed that 63 patients had positive antibodies in the following percentages: $0.16 \%$ of the patients had EMA, $5.7 \%$ had IgA antigliadin antibodies, and $4.4 \%$ had IgG anti-gliadin antibodies. In addition, 25 duodenal biopsies were conducted, but none of the patients presented with celiac disease ${ }^{17}$. Together, these findings demonstrate that the association between celiac disease and chronic hepatitis $\mathrm{C}$ remains poorly defined.

However, there is a large amount of evidence indicating that $\mathrm{HCV}$ is directly involved in the pathogenesis of mixed cryoglobulinemia. For example, anti-HCV antibodies and viral RNA were isolated from the cryoprecipitate of a large number of patients with this disorder ${ }^{30}$. In this work, the testing for cryoglobulins was positive in $2.1 \%$ of the patients, which differs from the results in other studies showing that the prevalence of cryoglobulins in patients with HCV ranges from 35 to $54 \%{ }^{13,31-33}$. Such differences may be justified by technical difficulties in sample processing, which involves the cooling of serum samples at $4^{\circ} \mathrm{C}$ for at least $72 \mathrm{~h}$ and the observation of a precipitate formation that is reversible by heat. The most common sources of error are false-negative results due to loss of the cryoprecipitate during transport and storage ${ }^{32}$. Therefore, more than one sample should be assessed in patients with negative results and in cases of high clinical suspicion. In addition, the low prevalence of cryoglobulinemia observed may be due to the use of only a single sample to define positive and negative results.

The prevalence of NOSA in this study was $24.2 \%$, which is similar to that found in the United States (20.0 to $22 \%)^{6,34}$ and Europe (25.0 to $36.9 \%)^{10,35-37}$, in which the same dilution was used as the cut-off point (1:40, as recommended for adults) ${ }^{38}$. SMAs are immunoglobulins that react with filaments of the cytoskeleton, including microfilaments (actin and vinculin), 
intermediate filaments (vimentin and desmin) and microtubules (tubulin). The pattern involving the vessels, glomeruli and tubules is more specific for autoimmune hepatitis, while the vessel pattern is more frequently observed in $\mathrm{HCV}$ infection. Despite the fact that SMAs are often detected in autoimmune hepatitis $^{39}$, these are defined as NOSA because they can also be found, with a variable prevalence, in infectious diseases and some types of tumors ${ }^{40}$. SMAs are most frequently found in patients with $\mathrm{HCV}$, at a prevalence that varies from $13.3 \%$ to $66 \% \%^{6,35,36,41}$, which is comparable to the prevalence shown in this study (26.7\%). LKM1 is a less common NOSA, with a prevalence ranging from $2.4 \%$ in the United $\operatorname{States}^{6}$ and 2.2 to $8.1 \%$ in Italy ${ }^{35,36,}$, which is also consistent with the results presented in this paper $(6.8 \%)$.

In the United States, Wandstrat et al. found low ANA titers in approximately $27 \%$ of healthy individuals, with a $2.5 \%$ prevalence of significantly higher levels ${ }^{42}$. In Sweden, the prevalence of ANAs was described as $6.7 \%$ of healthy individuals ${ }^{43}$. Esteves et al. found a prevalence of $12.6 \%$ for ANAs in Brazilian children and adolescents ${ }^{44}$. The presence of ANAs may be a sign of autoimmune hepatitis and other inflammatory conditions such as systemic lupus erythematosus ${ }^{45,46}$. Although ANAs can be present in these diseases, in the cases of individuals with $\mathrm{HCV}$, these typically signify only an epiphenomenon ${ }^{11,47}$. The incidence of ANA among individuals infected with $\mathrm{HCV}$ is higher than that of the general population, ranging from 4.4 to $23 \%^{12,35,36,41,47,48}$, a rate similar to the $7.6 \%$ prevalence evidenced in this study. There are four major types of immunofluorescence patterns for ANA: nuclear, speckled, nucleolar and homogeneous. These patterns reflect antibodies against specific nuclear antigens and vary according to the disease ${ }^{49}$. A standard ANA is not defined in relation to liver diseases, although there is greater association of homogeneous and speckled patterns with autoimmune hepatitis ${ }^{50}$. In patients with $\mathrm{HCV}$, the speckled pattern is described most frequently and was shown to be present in 68 to $91 \%$ of patients with positive ANA ${ }^{12,47}$.

The connection between the presence of NOSA and the clinical, biochemical and histological particularities of patients with HCV is controversial. As presented in Table 2, NOSA positivity was associated with pathologic liver function parameters, including higher levels of AP and lower levels of platelets and prothrombin activity. Abuaf et al. researched the prevalence of autoantibodies in 272 individuals with chronic hepatitis C. This study examined 100 blood donor controls not infected with HCV, 72 patients with autoimmune hepatitis, 74 patients with hepatitis B and 30 patients with alcoholic hepatitis or cirrhosis, and no differences were found in the levels of aminotransferases and $\mathrm{GGT}^{51}$ among the patients with $\mathrm{HCV}$ who presented with LKM1 antibodies. Clifford et al. retrospectively assessed the presence of autoantibodies in 117 patients with hepatitis $\mathrm{C}$ and tested 41 of these patients for the presence of LKM1 antibodies. When the presence of NOSA was associated with the severity of liver disease, no significant difference was found ${ }^{6}$. Yee et al. investigated the presence of ANAs in 645 individuals receiving hepatitis $\mathrm{C}$ pre- treatment in 3 centers, including 225 individuals in Sweden, 207 in the United Kingdom and 213 in Italy. The liver biopsies of these patients were evaluated by the same pathologist, and no correlation was found between ANA positivity and its pattern, increased inflammatory activity and progression to fibrosis ${ }^{12}$. Despite the findings of these studies ${ }^{6,12,35,52}$, the association of altered liver function tests have been previously reported by different authors ${ }^{10,11,37,53}$. Over a 3-year period, Lenzi et al. examined 226 individuals with $\mathrm{HCV}$ in comparison to 2 other groups, including 226 anti-HCV negative individuals and 87 HBsAg-positive patients. In the patients with $\mathrm{HCV}$, the presence of NOSA was independently associated with abnormal levels of ALT $(p<0.001)$ and GGT $(p<0.05)$. Moreover, the ALT alterations were associated with the presence of SMA $(p<0.05)$, and the GGT alterations were associated with the presence of ANA $(p<0.05)$. The risk of cirrhosis and/or hepatocellular carcinoma was 3.8 times greater in cases where the presence of SMA and genotype $1 \mathrm{~b}(\mathrm{p}<0.05)$ occurred in a concomitant way. However, the association between the presence of NOSA in anti-HCV negative and HBsAg-positive individuals was not shown $^{37}$. In a study conducted by Cassani et al., 290 patients with chronic hepatitis $\mathrm{C}$ were compared to 35 patients with type 1 autoimmune hepatitis regarding NOSA positivity and its clinical impact on disease. In an independent way, in HCV patients, the presence of autoantibodies was associated with higher levels of ALT $(\mathrm{p}=0.0009)$ and more severe periportal necroinflammation $(\mathrm{p}=0.003)^{10}$.

We acknowledge some limitations to our analysis. First, the use of retrospectively collected data may have led to selection bias. However, bias was unlikely in this study because demographic, clinical, laboratory and histological characteristics of the included patients were assessed according to a standardized protocol. Second, autoantibodies and cryoglobulins were tested only once, and two or more tests could have improved the sensitivity of the screening. However, these patients were asymptomatic for autoimmune manifestations, so we feel that a single test was reasonable. Third, the external validity of this study could be questioned because only our hospital patients were included in the data analysis, but our study population characteristics were similar to those described elsewhere.

In this study, among the NOSA-positive individuals, there was a statistically significant alteration of hepatic test results such as higher levels of AP and lower levels of platelets and prothrombin activity. We also observed a greater proportion of NOSA-positive patients with significant fibrosis and a tendency towards more marked periportal inflammatory activity. The presence of NOSA in these patients has been interpreted as a secondary manifestation of hepatocellular damage favored by genetic factors of the host ${ }^{54}$. We conclude that the prevalence of autoantibodies among individuals with hepatitis $\mathrm{C}$ is similar to that described by other authors, despite the low prevalence of cryoglobulins. Moreover, NOSA positivity was related to alterations in the biochemical hepatic tests and to higher degrees of fibrosis, which contributes to the hypothesis that these values reflect the severity of the underlying liver lesion. 


\section{CONFLICT OF INTEREST}

The authors declare that there is no conflict of interest.

\section{REFERENCES}

1. World Health Organization (WHO). Hepatitis C - 2002. Geneva: WHO; 2003.

2. Farci P, Alter HJ, Wong D, Miller RH, Shih JW, Jett B, et al. A long-term study of hepatitis C virus replication in non-A, non-B hepatitis. N Engl J Med 1991; 325:98-104.

3. Thein HH, Yi Q, Dore GJ, Krahn MD. Estimation of stage-specific fibrosis progression rates in chronic hepatitis $\mathrm{C}$ virus infection: a meta-analysis and meta-regression. Hepatology 2008; 48:418-431.

4. Gomaa AI, Khan SA, Toledano MB, Waked I, Taylor-Robinson SD. Hepatocellular carcinoma: epidemiology, risk factors and pathogenesis. World J Gastroenterol 2008; 14:4300-4308.

5. Obermayer-Straub P, Manns MP. Hepatitis $C$ and D, retroviruses and autoimmune manifestations. J Autoimm 2001; 16:275-285.

6. Clifford BD, Donahue D, Smith L, Cable E, Luttig B, Manns M, et al. High prevalence of serological markers of autoimmunity in patients with chronic hepatitis C. Hepatology 1995; 21:613-619.

7. Bogdanos DP, McFarlane IG. Cytochrome P450 2A6 meets P450 2D6: an enigma of viral infections and autoimmunity. J Hepatol 2003; 39:860-863.

8. Lenzi M, Ballardini G, Fusconi M, Cassani F, Selleri L, Volta U, et al. Type 2 autoimmune hepatitis and hepatitis $C$ virus infection. Lancet 1990; 335:258-259.

9. Strassburg CP, Manns MP. Autoimmune hepatitis versus viral hepatitis C. Liver $1995 ; 15: 225-232$.

10. Cassani F, Cataleta M, Valentini P, Muratori P, Giostra F, Francesconi R, et al. Serum autoantibodies in chronic hepatitis C: comparison with autoimmune hepatitis and impact on the disease profile. Hepatology 1997; 26:561-566.

11. Narciso-Schiavon JL, Freire FC, Suarez MM, Ferrari MV, Scanhola GQ, Schiavon LL, et al. Antinuclear antibody positivity in patients with chronic hepatitis C: clinically relevant or an epiphenomenon? Eur J Gastroenterol Hepatol 2009; 21:440-446.

12. Yee LJ, Kelleher P, Goldin RD, Marshall S, Thomas HC, Alberti A, et al. Antinuclear antibodies in chronic hepatitis $\mathrm{C}$ virus infection: correlates of positivity and clinical relevance. J Viral Hepat 2004; 11:459-464.

13. Cicardi M, Cesana B, Del Ninno E, Pappalardo E, Silini E, Agostoni A, et al. Prevalence and risk factors for the presence of serum cryoglobulins in patients with chronic hepatitis C. J Viral Hepat 2000; 7:138-143.

14. Lunel F, Musset L, Cacoub P, Frangeul L, Cresta P, Perrin M, et al. Cryoglobulinemia in chronic liver diseases: role of hepatitis $\mathrm{C}$ virus and liver damage. Gastroenterology 1994; 106:1291-1300.

15. Ruggeri C, La Masa AT, Rudi S, Squadrito G, Di Pasquale G, Maimone S, et al. Celiac disease and non-organ-specific autoantibodies in patients with chronic hepatitis C virus infection. Dig Dis Sci 2008; 53:2151-2155.

16. Durante-Mangoni E, Iardino P, Resse M, Cesaro G, Sica A, Farzati B, et al. Silent celiac disease in chronic hepatitis C: impact of interferon treatment on the disease onset and clinical outcome. J Clin Gastroenterol 2004; 38:901-905.

17. Thevenot T, Denis J, Jouannaud V, Monnet E, Renou C, Labadie H, et al. Celiac disease in chronic hepatitis $\mathrm{C}$ : a French multicentre prospective study. Aliment Pharmacol Ther 2007; 26:1209-1216.

18. Preziati D, La Rosa L, Covini G, Marcelli R, Rescalli S, Persani L, et al. Autoimmunity and thyroid function in patients with chronic active hepatitis treated with recombinant interferon alpha-2a. Eur J Endocrinol 1995; 132:587-593.

19. Fernandez-Soto L, Gonzalez A, Escobar-Jimenez F, Vazquez R, Ocete E, Olea $\mathrm{N}$, et al. Increased risk of autoimmune thyroid disease in hepatitis $\mathrm{C}$ vs. hepatitis before, during, and after discontinuing interferon therapy. Arch Intern Med 1998; 158:1445-1448.

20. Gayotto LCC. Visão histórica e consenso nacional sobre a classificação das hepatites crônicas. Comitê da Sociedade Brasileira de Patologia e da Sociedade Brasileira de Hepatologia. Gastroenterol Endosc Dig 2000; 19:137-140.
21. Ministério da Saúde, Secretaria de Vigilância em Saúde, Departamento de Aids, DST e hepatites virais. Boletim Epidemiológico Hepatites Virais. Brasília: Ministério da Saúde; 2011. p. 1-82.

22. Murphy EL, Bryzman SM, Glynn SA, Ameti DI, Thomson RA, Williams AE, et al. Risk factors for hepatitis $\mathrm{C}$ virus infection in United States blood donors. Hepatology 2000; 31:756-762.

23. Seeff LB, Buskell-Bales Z, Wright EC, Durako SJ, Alter HJ, Iber FL, et al. Long-term mortality after transfusion-associated non-A, non-B hepatitis. N Engl J Med 1992; 327:1906-1911.

24. Andrade LJ, Melo PR, Atta AM, Atta ML, Jesus LS, Sousa GM, et al. Smooth muscle antibodies and cryoglobulinemia are associated with advanced liver fibrosis in Brazilian hepatitis C virus carriers. Braz J Infect Dis 2011; 15:66-68.

25. Relatório do Grupo de Estudo da Sociedade Brasileira de Hepatologia. Epidemiologia da infecção pelo vírus da hepatite C no Brasil. Gastroenterol Endosc Dig 1999; 18:53-58.

26. Ganne-Carrie N, Medini A, Coderc E, Seror O, Christidis C, Grimbert S, et al. Latent autoimmune thyroiditis in untreated patients with $\mathrm{HCV}$ chronic hepatitis: a case-control study. J Autoimmun 2000; 14:189-193.

27. Duclos-Vallee JC, Pateron D, Joannet C, Duron F, Homber JC, Beaugrand M. High prevalence of anti-HCV antibodies in patients with Hashimoto's thyroiditis. BMJ 1994; 309:846-847.

28. Yang R, Shan Z, Li Y, Fan C, Li C, Teng W. Prevalence of thyroid autoantibodies in hepatitis C and hepatitis B infection in China. Intern Med 2011; 50:811-815.

29. Fine KD, Ogunji F, Saloum Y, Beharry S, Crippin J, Weinstein J. Celiac sprue: another autoimmune syndrome associated with hepatitis C. Am J Gastroenterol 2001; 96:138-145.

30. Agnello V, Abel G. Localization of hepatitis C virus in cutaneous vasculitic lesions in patients with type II cryoglobulinemia. Arthritis Rheum 1997; 40:2007-2015.

31. Lunel F, Musset L, Cacoub P, Frangeul L, Cresta P, Perrin M, et al. Cryoglobulinemia in chronic liver diseases: role of hepatitis $\mathrm{C}$ virus and liver damage. Gastroenterology 1994; 106:1291-1300.

32. Wong VS, Egner W, Elsey T, Brown D, Alexander GJ. Incidence, character and clinical relevance of mixed cryoglobulinemia in patients with chronic hepatitis C virus infection. Clin Exp Immunol 1996; 104:25-31.

33. Adinolfi LE, Utili R, Attanasio V, Zampino R, Ragone E, Tripodi MF. Epidemiology, clinical spectrum and prognostic value of mixed cryoglobulinemia in hepatitis C virus patients: a prospective study. Ital J Gastroenterol 1996; 28:1-9.

34. Czaja AJ, Carpenter HA, Santrach PJ, Moore SB, Taswell HF. Evidence against hepatitis viruses as important causes of severe autoimmune hepatitis in the United States. J Hepatol 1993; 18:342-352.

35. Stroffolini T, Colloredo G, Gaeta GB, Sonzogni A, Angeletti S, Marignani M, et al. Does an 'autoimmune' profile affect the clinical profile of chronic hepatitis C? An Italian multicentre survey. J Viral Hepat 2004; 11:257-262.

36. Muratori P, Muratori L, Guidi M, Granito A, Susca M, Lenzi M, et al. Clinical impact of non-organ-specific autoantibodies on the response to combined antiviral treatment in patients with hepatitis C. Clin Infect Dis 2005; 40:501-507.

37. Lenzi M, Bellentani S, Saccoccio G, Muratori P, Masutti F, Muratori L, et al. Prevalence on non-organ specific autoantibodies and chronic liver disease in the general population: a nested case-control study of the Dionysus cohort. Gut 1999; 45:435-441.

38. Johnson PJ, McFarlane IG. Meeting report: International Autoimmune Hepatitis Group. Hepatology 1993; 18:998-1005.

39. Manns MP, Czaja AJ, Gorham JD, Krawitt EL, Mieli-Vergani G, Vergani D, et al. Diagnosis and management of autoimmune hepatitis. Hepatology 2010; 51:2193-2213.

40. Toh BH. Smooth muscle autoantibodies and autoantigens. Clin Exp Immunol $1979 ; 38: 621-628$.

41. Zusinaite E, Metskula K, Salupere R. Autoantibodies and hepatitis C virus genotypes in chronic hepatitis $\mathrm{C}$ patients in Estonia. World J Gastroenterol 2005; 11:488-491.

42. Wandstrat A, Carr-Johnson F, Branch V, Gray H, Fairhurst A, et al. Autoantibody profiling to identify individuals at risk for systemic lupus erythematosus. J Autoimmun 2006; 27:153-160. 
43. Eriksson C, Kokkonen H, Johansson M, Hallmans G, Wadell G, RantapääDahlqvist $\mathrm{S}$. Autoantibodies predate the onset of systemic lupus erythematosus in northern Sweden. Arthritis Res Ther 2011; 13:2-8.

44. Hilário MO, Len CA, Roja SC, Terreri MT, Almeida G, Andrade LE. Frequency of antinuclear antibodies in healthy children and adolescents. Clin Pediatr 2004; 43:637-642.

45. Czaja AJ, Cassani F, Cataleta M, Valentini P, Bianchi FB. Antinuclear antibodies and patterns of nuclear immunofluorescence in type 1 autoimmune hepatitis. Dig Dis Sci 1997; 42:1688-1696.

46. Hietarinta M, Lassila O. Clinical significance of antinuclear antibodies in systemic rheumatic diseases. Ann Med 1996; 28:283-291.

47. Peng YC, Hsieh SC, Yang DY, Tung CF, Hu WH, Huang WN, et al. Expression and Clinical Significance of Antinuclear Antibody in Hepatitis C Virus Infection. J Clin Gastroenterol 2001; 33:402-406.

48. Zauli D, Cassani F, Bianchi FB. Auto-antibodies in hepatitis C. Biomed Pharmacother 1999; 53:234-241.
49. White RH, Robbins DL. Clinical significance and interpretation of antinuclear antibodies. West J Med 1987;147:210-213.

50. Czaja AJ, Nishioka M, Morshed SA, Hachiya T. Patterns of nuclear immunofluorescence and reactivities to recombinant nuclear antigens in autoimmune hepatitis. Gastroenterology 1994; 107:200-207.

51. Abuaf N, Lunel F, Giral P, Borotto E, Laperche S, Poupon R, et al. 1. Non-organ specific autoantibodies associated with chronic $\mathrm{C}$ virus hepatitis. J Hepatol 1993; 18:359-364.

52. Muratori P, Muratori L, Stroffolini T, Pappas G, Terlizzi P, Ferrari R, et al. Prevalence of non-organ specific autoantibodies in HCV-infected subjects in the general population. Clin Exp Immunol 2003;131:118-121.

53. Chrétien P, Chousterman M, Abd Alsamad I, Ozenne V, Rosa I, Barrault C, et al. Non-organ-specific autoantibodies in chronic hepatitis $\mathrm{C}$ patients: association with histological activity and fibrosis. J Autoimmun 2009; 32:201-205.

54. Czaja AJ, Carpenter HA, Santrach PJ, Moore SB. Immunologic features and HLA associations in chronic viral hepatitis. Gastroenterology 1995; 108:157-164. 